\title{
Historical objections against the number line
}

\begin{abstract}
Albrecht Heeffer
Abstract

Historical studies on the development of mathematical concepts will help mathematics teachers to relate their students' difficulties in understanding to conceptual problems in the history of mathematics. We argue that one popular tool for teaching about numbers, the number line, may not be fit for early teaching of operations involving negative numbers. Our arguments are drawn from the many discussions on negative numbers during the seventeenth and eighteenth centuries from philosophers and mathematicians such as Arnauld, Leibniz, Wallis, Euler and d'Alembert. Not only does division by negative numbers pose problems for the number line, but even the very idea of quantities smaller than nothing has been challenged. Drawing lessons from the history of mathematics, we argue for the introduction of negative numbers in education within the context of symbolic operations.
\end{abstract}

Keywords: negative numbers, number line, obstacles

My enthusiasm for mathematics was based principally perhaps on my horror of hypocrisy; hypocrisy as I saw it, was my aunt Séraphie, Mme Vignon and their priests. In my opinion hypocrisy wasn't possible in mathematics and, in my youthful simplicity, I thought the same went for all the sciences in which I had heard it said they were applied. What then when I realized that no one could explain to me how it is that a minus times a minus equals a plus?

(From The Life of Henry Brulard, pseudonym for Marie-Henri Beyle, better known as Stendhal, 1890, ed. 2002, pp. 363-4)

\section{Introduction}

The number line is currently one of the important tools for teaching basic arithmetical concepts such as natural and real numbers in primary and secondary education. Hans Freudenthal $(1983,101)$ calls this mental object a "device beyond praise" and considers it a preferred vehicle to teach negative numbers (ibid, 437). In many countries the ordering of negative numbers by means of the number line is taught by the fifth grade (Howson, Harries and Sutherland, 1999).

Despite its wide acceptance, the use of the number line in mathematics education is rather new. It seems to have originated in the 1950s. ${ }^{1}$ Max Beberman, credited for many innovations in math teaching, used the earlier term 'number scale': "In teaching subtraction of signed numbers, I first draw a number scale" (Beberman and Meserve, 1956).

As pointed out by Susan Carey (2001) the number line should be considered as a cultural construction - and most probably as a Western construction - rather than an

${ }^{1}$ A systematic study of the history of the number line in mathematics education still needs to be undertaken. However some web sites reconstructed its history: Jeff Miller, http://jeff560.tripod.com/mathword.html and Patt Ballew http://www.pballew.net/mathbooks.html are the most useful (retrieved 1 Nov 2010). 
arithmetical model with ontogenetic foundations as proposed by naturalists such as Stanislas Dehaene (1997).

However, not everyone is convinced of the benefits of using the number line for teaching negative numbers in primary education. In fact, the very teaching of operations on negative numbers is no longer allowed in education below the age of 12 in Belgium. Negative numbers can only be used in "concrete situations". The examples provided are the floors of a building and the temperature scale. The concept of an isolated negative number is an intrinsically difficult concept. Negative numbers emerged in history within the context of symbolic algebra (Heeffer 2010). We share the view of some national education programs that the concept is best taught in secondary education and more specifically within an algebraic context. We will develop some arguments from the history of mathematics against the use of the number line for teaching on negative numbers.

Even the question of the historical acceptance of negative numbers is problematic. The interpretation of negative solutions given in two accounts on the history of the subject (Sesiano 1985 and Gericke 1996) is challenged by others as not being cases of acceptance of negative quantities (Heeffer 2007). The algebraic practice of solving linear problems has led repeatedly to situations in which one arrives at "a negative value". Before the sixteenth century, such solutions were consistently called 'absurd' or 'impossible'. The abbaco master, convinced of the correctness of his algebraic derivations, could interpret the negative value in a merchant's context as a debt. ${ }^{2}$ This does not imply that he accepted the solution as a negative value. On the contrary, by interpreting the solution as a debt, he removed the negative. Only from the beginning of the sixteenth century onwards, we see the first step towards negative values in the form of algebraic terms affected by a negative sign. The fact that negative solutions were considered absurd for several centuries of algebraic practice is of significance to the teaching of mathematics. The arguments we will expound below were advanced and discussed by philosophers and mathematicians of the seventeenth and eighteenth century. The continuous struggle during that period to get a grip on such an elusive concept as that of a negative quantity exemplifies the intrinsic epistemic difficulty of some elementary concepts, now taught to ten year olds. The historical arguments and discussions are not trivial. They should be taken seriously by anyone teaching the subject. Questions arising in classroom practice may reflect historical concerns and positions taken by previous mathematicians.

\section{The number line as a model}

Many publications dealing with the number line in the history of mathematics or in mathematics education fail to give a definition (e.g. Thomaidis and Tzanakis, 2007). Let us here make clear how we will use the term. The number line is a representation of numbers on a straight line where points represent integers or real numbers and the distance between points matches the arithmetical difference between the corresponding numbers. The number line in Western culture is usually depicted horizontally with higher numbers

2 Abbaco masters or maestri d'abbaco were active in the commercial centers of Northern Italy between 1300 and 1550, teaching boys between eight and fourteen arithmetic with the use of Hindu-Arabic numerals. Abbaco or abbacus mathematics is spelled with double ' $b$ ' to distinguish it from the abacus as instrument. For a thorough introduction in abbaco mathematics, see Høyrup (2007). 
shown at the right hand side. Negative numbers are conventionally shown left from zero. The transition from positive to negative over zero is taken for granted.

Having defined the number line as a representation, it should be understood as a model for reasoning, teaching and understanding concepts and properties in mathematics. Models presuppose some kind of isomorphism between the model and what is modeled. Properties of a straight line can be exploited to model arithmetical properties. A straight line can be extended into infinity; so can natural numbers. A straight line has two directions; also negative integers can go to $-\infty$. The linear aspect of a line can be exploited as a scale, so that equal distances on the line always correspond to equal differences between numbers. This also applies to negative numbers. The fact that the distance between 2 and 5 on the number line is equal to the distance of 2 and -1 is a property that allows children to appeal to spatial intuitions for an understanding of negative numbers. The number line also provides an excellent model to relate real numbers to natural numbers. While $4 / 3$ is represented decimally by an infinite sequence of digits, it corresponds to exactly one point on the number line, located between 1 and 2.

As with all models, they fail when the isomorphism breaks down. This happens as soon as we start operating on numbers. Basic arithmetical notions such as proportions, multiplication and division already present challenges to the model, especially when they involve negatives. Good models can cope with some disturbances. The question we would like to pose here is how good the number line is as a model to teach operations involving negative quantities. Or put differently: do the benefits of using the number line weigh up against the challenges that operations on negatives pose? Is the transition over zero as intuitive as it is considered to be? We will demonstrate that, from a historical viewpoint, this is not the case. Our objections thus focus on the use of the number line for teaching on negative quantities. This does not exclude the use of the number line for other purposes in mathematics education. There are certainly didactical situations for which the number line is an adequate model.

\section{Epistemological obstacles and conceptual barriers}

When discussing the historical objections against the number line we cannot pass by the 'ontogeny recapitulates phylogeny'-debate. Some authors have taken the position that there is a strong parallel between the historical development of mathematical concepts and the acquisition of mathematical notions and concepts in the cognitive development of children. The parallel can go in both directions. In Psychogenèse et histoire des sciences, Piaget and Garcia (1983) identify major transitional mechanisms in geometry and algebra and relate them to the three development stages in Piaget's theory of psychogenesis. Their account of the 3000 year history of algebra identifies major stages of its historic development with the three corresponding stages of cognitive development. The first (long) period was only concerned with "solutions to specific equations. The methods used were purely empirical, trial-and-error. Each equation was treated as a separate object. This is undoubtedly an intraoperational period" (ibid, 166). The second, interoperational period started in the eighteenth century and covers Lagrange and Gauss. This period is characterized by "transformations of equations that allow the reduction of an unsolvable form to one that is solvable" (ibid.). Finally, the transoperational period originates with the group theory of Galois (1811-1832), going from equations to more abstract structures. 
This approach by Piaget has received little support from historians or scholars working on the crossover between history and pedagogy of mathematics.

Far more accepted is the idea that conceptual difficulties in the historical development of mathematics may be reflected in mathematics education. The most common framework for approaching this parallel is that of epistemological obstacles, a term coined in 1938 by Bachelard within the context of history of science. The term originally refers to misleading elements blocking the rational process of advancement of science. The idea was adapted by Brousseau (1976) for use in mathematics education. Brousseau attributes a positive function to epistemological obstacles within his didactical project. He considers such obstacles more as a piece of mathematical knowledge rather than a lack of knowledge. He identifies them in the history of mathematics as well as students' spontaneous models. In classroom situations they do not appear as erratic or unexpected errors, but as predictable ones. In a reaction to Brousseau, Glaeser (1981) listed a number of epistemological obstacles including the "inability to manipulate isolated negative quantities" and "the difficulty of giving meaning to isolated negative quantities". While the idea of epistemological obstacles is still at the forefront in the 'ontogeny recapitulates phylogeny'-debate, several authors have called for caution and warned that the parallelism should not be taken all too literally. Herscovics (1989) pointed out that the conditions under which concepts are thought in today's classroom are quite different from the historical conditions in which these concepts matured. Thomaidis and Tzanakis (2007) in a study on the use of the number line conclude that a strict parallelism is untenable and propose a more subtle one.

While we believe in a strong parallelism between history and education for some intrinsic difficult concepts such as negative numbers, it is not necessary to resort to epistemological obstacles as a theoretical framework. We see two main objections against the concept. Within the context of history, epistemological obstacles are often viewed as blocking factors within a teleological evolution of mathematics. Such a view is considered dubious from a current perspective of mathematical practice which attributes a high degree of contingency to the development of mathematics. On the level of mathematics education, epistemological obstacles are mostly situated on the psychological level. Current scholarship takes into account a much broader contextual perspective including sociological and cultural conventions as well as norms and values. A useful alternative to epistemological obstacles is available from the history of science. An interesting phenomenon in scientific discovery is simultaneous discovery. A good example of this is the discovery of the sine law of refraction. As is now established, the sine law was discovered independently by Thomas Harriot around 1602, by Willebrord Snellius in 1621 and by René Descartes between 1626 and 1628. Descartes was the first to publish the law in his Dioptrique of 1637 . With accurate data available since Ptolemy ( $2^{\text {nd }}$ century AD), why did it take fifteen centuries to come to the sine law? Furthermore, why did several individuals came to the discovery within a matter of a few decades? The barrier theory by Margolis (1993) provides a framework for the understanding of such historical cases. Habits of minds govern our cognitive processes and are similar to what Polanyi called 'tacit knowledge'. They can be considered critical intuitions within a community and are therefore constitutive of a paradigm. A barrier is an entrenched habit of mind that can block a cognitive breakthrough. In relation to our subject, negative quantities in mathematics, the cognitive barrier is symbolic reasoning. It took about two centuries from 
a first acceptance of isolated negative quantities to a fully symbolic treatment of the operations involved. Particularly for symbolic reasoning, the conceptual barrier functions in two directions. The conceptual distance between the prevailing arithmetical interpretation of abbaco algebra and the conflicting new ideas about symbolic reasoning in the sixteenth century determined the long historical process of difficulties. In the reverse direction, we are now so accustomed to symbolic reasoning that it becomes equally difficult to understand non-symbolic reasoning in algebraic treatises before Descartes.

In the discussion that follows, on the historical objections against the number line, we will consider the symbolic treatment of negative quantities and operations on negative quantities as a conceptual barrier. We would like to argue that it is not so much the concept of negative quantities in itself that has led to problems and conflicts but rather the idea that negative quantities and their operations should be considered on a symbolic and abstract level. This will lead us to the conclusion that operations on negative quantities are best introduced in mathematics education within the context of symbolic algebra.

\section{Numbers smaller than nothing}

\subsection{Antoine Arnauld (1612-1694)}

Antoine Arnauld, who wrote an important philosophical work known as The Logic of Port-Royal (Arnauld, 1662) published also his Geometry (Arnauld, 1667). In the book he includes an example of symbolic rules that he considers to be against our basic intuitions on magnitudes and proportions. Although he did not devise the argument as a dispute against the number line, he did provide a strong argument against its use for teaching negative numbers. Take any point $n$ on the line of natural numbers, the proportion of its neighbors $n+1$ to $n-1$ is always larger than the proportion of $n-1$ to $n+1$. This property disappears when you add negative numbers to the number line.

He explains it as follows: Suppose we have two numbers, a larger and a smaller one. The proportion of the larger to the smaller one should evidently be larger than the proportion of the smaller to the larger one. But if we use 1 as the larger number and -1 as the smaller one this would lead to

$$
\frac{1}{-1}>\frac{-1}{1}
$$

which is against the rules of algebra. ${ }^{3}$ Witnessing the multiple instances in which this discussion turns up during the seventeenth century, the clash between symbolic reasoning and classic proportion theory, taught within the quadrivium, was experienced as problematic. Schrecker (1935) was the first to describe the controversy on the topic initiated by Prestet in his Elemens des mathematiques of 1675. Both Mancosu (1996, 8891) and Schubring (2005, 52-61) describe the positions taken. Prestet's response was basically that quantities can only be positive and that the signs refer to operations. So it is

\footnotetext{
3 We take the liberty to represent proportions by fractions within an algebraic context. This is by no means anachronistic as is shown in a problem of Jacopo da Firenze (Høyrup 2007, 314, ms. f. 39 ${ }^{\mathrm{v}}$ ). The enunciation of a problem about the profit made on a business trip is stated in terms of proportions. However, as soon as Maestro Jacopo applies algebra to solve the problem, the proportions are treated as fractions involving the cosa (the unknown). The conflation of proportions and fractions is common in abbaco algebra.
} 
perfectly possible to subtract a larger quantity from a smaller one. The negative result means just that: a larger quantity subtracted from a smaller one. And when dealing with geometrical ratios one should neglect the signs all together.

\subsection{Gottfried Wilhelm Leibniz (1646 - 1716)}

Also Leibniz found it important enough to respond to Arnauld in an article (Leibniz, 1712, 167) (see Figure 1).

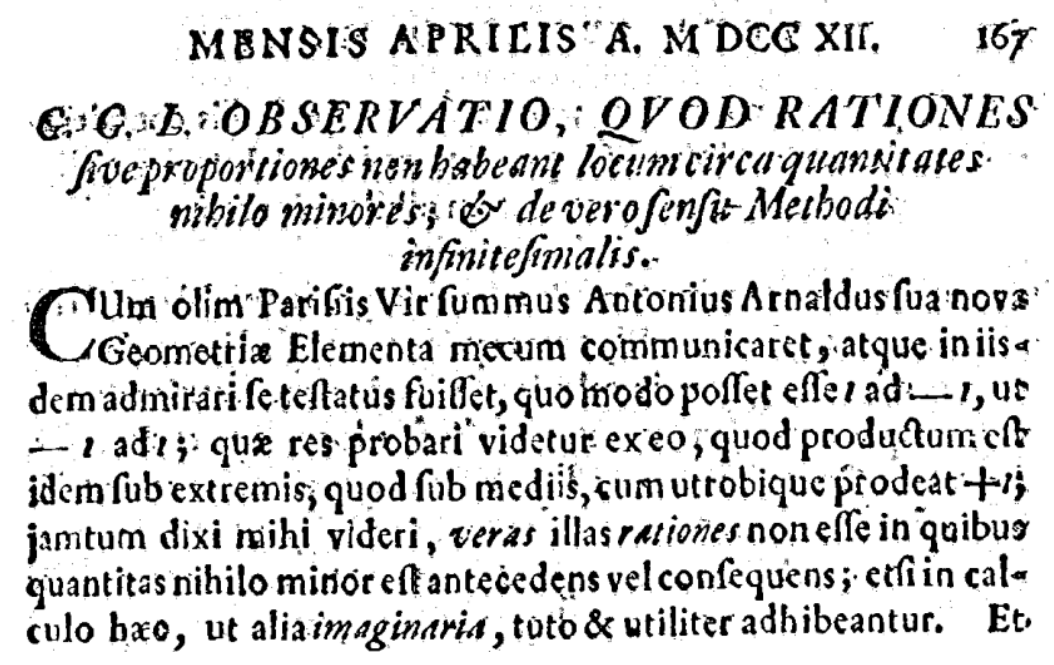

Figure 1: Leibniz's response to Arnauld in Acta eruditorum of 1712

Leibniz acknowledges the problem as a genuine one, but states that the division should be performed as a symbolic calculation, the same way as we do with imaginary numbers. Indeed, when blindly applying the rules of signs there is no problem at all. When dividing a positive number by a negative one, the result is negative, and dividing a negative number by a positive one, the result is also negative. Leibniz position can therefore be paraphrased as:

$$
\frac{1}{-1}=-\frac{1}{1}
$$

Leibniz's response to Arnauld exemplifies the evolution which had taken place in mathematics from the beginning of the sixteenth century. The operations of algebra, introduced in Europe mainly through Latin translations of Arabic works, were given new foundations by humanist mathematicians such as François Viète. By the end of the sixteenth century, new epistemic foundations were devised the basic operations of algebra. In his Isagoga of 1591, Viète constructed a new vocabulary for these operations, such as zetetics, poristics, exegetics, antithesis and hypobibasmo. Because of the strong belief in the correctness of these operations, the numerical results arrived at had to be accepted, even when they lead to anomalous results such as negative and imaginary numbers. The abstraction of the concrete numerical values in problem solving was one of the main achievements of symbolic algebra. That is where Leibniz is referring to.

\subsection{The abbaco tradition (1200-1500)}

It may be surprising when you follow the seventeenth-century discussions but the kind of symbolic reasoning proposed by Leibniz was well accepted within the abbaco tradition in Italy by the end of the fifteenth century. Although symbols were not used in any consistent way within this tradition we find that the maestri d'abbaco had no problems with such 
kind of symbolic operations. It has been argued that the introduction of symbols such as the minus and plus signs is the result of a process toward symbolic thinking (Heeffer 2008). The epistemic validity of operations on negative numbers within the abbaco tradition was derived from a belief in the correctness of generally accepted practices. Very early within the algebraic practice of the maestri d'abbaco we see 'proofs' for the rules of sign. That was the kind of explanation Henry Brulard, or Stendhal, preferred (see quote at the beginning). The first of such proofs in European mathematics appears in a treatise of 1344 by Maestro Dardi. ${ }^{4}$ It explains why a negative multiplied by a negative makes a positive. It is repeated in various other manuscripts dealing with algebra during the fifteenth century. The proof is derived from the well-know operations on binomials which often appear in the introductions of such manuscripts. The reasoning goes as follows: we know that 8 times 8 makes 64 . Therefore $(10-2)$ times $(10-2)$ should also result in 64 . One well known multiplication procedure is called per casella, (literally by the pigeonhole) meaning cross-wise multiplication in which you add all the sub-products (see Swetz 1987, 201-205). You multiply 10 by 10, this makes 100, then 10 times -2 which is -20 and again 10 times -2 or -20 leaves us with 60 . The last product is -2 times -2 but as we have to arrive at 64 , this must necessarily be +4 . Therefore a negative multiplied by a negative always makes a positive. In modern terminology we would say that the proof is based on distributive law of arithmetic.

By the end of the fifteenth century we see the rules of signs expressed in a more formal way. Luca Pacioli is the first to formulate them in an abstract form without referring to specific types of quantities (see Figure 2).

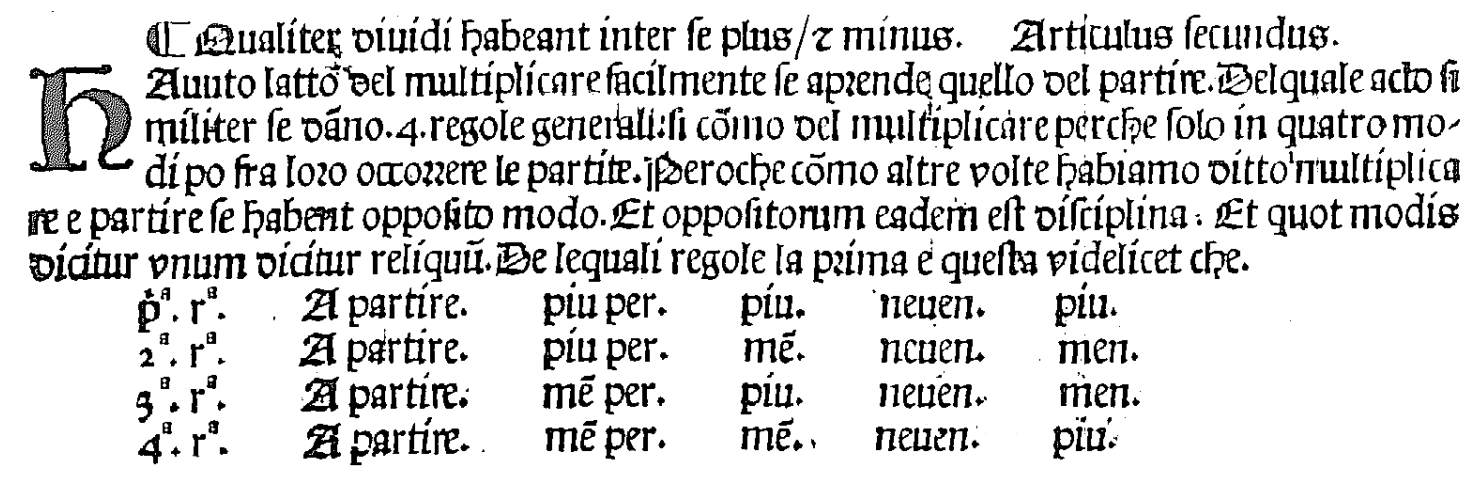

Figure 2: Pacioli's rules of sign for division from the Summa (1494, f. 113r)

Importantly, Pacioli introduced these rules in Distinction 8, as a preparation to his treatment of algebra. In contrast with the discussion of the basic operations of arithmetic, the rules of signs are formulated in the most general way. Except for an illustrating example with numbers, the formulation of the rules does not refer to any sort of quantities, integers, irrational binomials or algebraic terms. The rules only refer to 'the negative' and 'the positive'. Despite the absence of any symbolism, we consider this an early instance of symbolic reasoning. And as Leibniz said this is the way to deal with the apparent anomaly. Forget about the values but apply the rules correctly and you necessarily arrive at (0.2).

\footnotetext{
${ }^{4}$ His treatise is titled Aliabraa argibra and his best known for its 198 rules for solving "algebraic equations". There exist four extant copies of the manuscript, one of them published by Franci (2001, f. 5v, p.44). A critical edition based on the four manuscripts is being prepared by Warren Van Egmond. See also Høyrup (2010) for discussion of the proof.
} 


\section{A P V T XXII.}

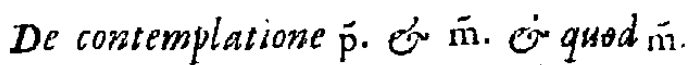
in $\tilde{\mathrm{m}}$. facit $\overline{\mathrm{m}}$. Oo de caufis borum iuxta veritatem.

C Vm dico 6. p. 2 . clarum eft, quod eft 8. ecundum rem:fed iuxta nomen eft cópolırum ex 6. \& 2. fmiliter cum dico $10 . \overline{\mathrm{m}}$. 2. fecundum rem eft 8 . iuxta nomen autem elt 10 . detracto. Et ideò in operatione quod ad finem attinet $6 . \bar{p} .2$.debet producere 64 . quia 8. in fe ductum producit 64.8 ita 10 . m.2. quia eft 8 . debet producere idem 64 . Sed quod ad modum operandi, quia 8 . eft diuifum in 6. p. 2. feu in 10. $\overrightarrow{\mathrm{m}}$. 2. oportet operari per guartam fecundi Euclidis. Et in 6.p. 2.eft manifeftum, $v e$ in figura ponatur a b $6 . b c_{2}$. fient a d I 2.de 4.d fiz. de 36. totum igitur 64. \& de hoc non elt dubiuni, fed fi ponatur a $\mathrm{c} 10 . \& \mathrm{~b} \mathrm{c}$ z. $\overline{\mathrm{m}}$. erit quadratum a çuihilominus 64 . id eft quadratum d e, quia a b verc eft 8 . Eft ergo ac, fi quis diceret habes agrum decem pedum quadratum, cuius duo pedesfunt alterius, \& quadratum parris tux eft tuum, reliquum totum eft alterius, igitur tu haberes d e folum, quod eft 64.25 gnomo ille $\mathrm{g} b$.f effer alterius, \& effet 36 . ve liquer.

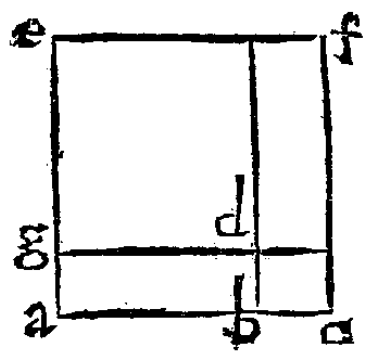

Figure 3: Cardano's refutation of the rules of sign

plus times plus makes minus.

The Aliza in the title of his treatise is derived from the Latin word a'izza meaning 'risky' or 'doubtful' (Tanner 1980, 162). Therefore the conclusion should not be taken too literality. As the same argument was repeated in his Sermo we will only discuss the first.

\footnotetext{
5 Both these instances are discussed by Heeffer (2007) and appear in chapter 37 of the Ars Magna named de regula falsum ponendis, or the "Rule of Postulating a Negative". Cardano adapts the rhetorical structure of abbaco treatises by posing $-x$ for the quantity to be sought and arrives at a positive value. However, by posing a negative unknown for the sought quantity he finds the argument of accepting a negative quantity as a solution to a linear problem. A similar abductive reasoning strategy is used for imaginary numbers.
}

Cardano made profound, albeit not wellrecognized contributions to the acceptance of negative numbers. He was the first to give a satisfactory argumentation for negative solutions to linear problems and the first to accept square roots of negative numbers. ${ }^{5} \mathrm{~A}$ justification of the correctness of operations leading to solutions with negative numbers was important to the development of symbolism because symbolic algebra makes abstraction from the arithmetical contents of the objects it is dealing with. We will further only sketch how Cardano formulated doubts about the rules of signs during his later writing career.

Some years before his death Cardano wrote two treatises in which he reflects on his earlier treatment of negative and imaginary numbers in the Ars Magna (1545). The first one is titled De Aliza Regulae published in 1570 as part of the larger De Propotionibus and the second Sermo de plus and minus which was published posthumously in his collected works (Cardano 1663, IV, 435-439). Of particular interest is his 'refutation' of the proof for the rules of signs as it was generally accepted by the abbacists. Using the same example as Maestro Dardi he concludes the contrary, that minus time minus makes plus could have the same validity as saying that 
The reasoning goes as follows (see his diagram in Figure 3). If we multiply 10 by 10 we get a square with side $a c$ equal to 10 and area 100 . Given that $b c$ and $a g$ equal 2 , the square $e g d$ thus has an area of 64. To get from 100 (square acef) to 64 (square egd) we therefore have to subtract the two rectangles $c g$ and $b f$. But by doing so we have subtracted the square $c d$ twice, so we have to add it one more time. Thus arithmetically we have

$100-(10 \times 2)-(10 \times 2)+(2 \times 2)=64$.

And this is the expansion of $(10-2)(10-2)$ as we have seen it in the proof of Maestro Dardi. But Cardano argues that the +4 is not the result of the multiplication of -2 by -2 but an area we must add again because we had subtracted the square twice. He refers to proposition II.7 of Euclid's Elements and concludes: "And this shows the common error of those who say that minus times minus produces plus, lest indeed it be more correct that minus times minus produces plus than plus times plus would produce minus". 6 Thus Cardano points out that the above argument is purely geometric, and that from an arithmetic point of view there is no a priori reason to suppose that $m \cdot m=p$.

While Cardano doubts the rules of signs for multiplication (and also for division, see Tanner 1980, 167) on this occasion he does not err on their application to algebraic problems. So why his fulmination against it? While Tanner believes that Cardano "appears unique only in putting into print something of a rebel trend of thought, entertained in private by the majority, but soon to be disavowed by silent suppression", Schubring (2005, 45) believes in epistemological motives as Cardano experienced the mixture of operations of subtraction with those of multiplication as problematic. For us, the curious use of the same example from the well known proof of Dardi suggests that Cardano's motivation stems from a lack of epistemic validity for the generally accepted rules of sign. The justification for the rules of signs given by Maestro Dardi and abbaco masters after him is not sufficient for Cardano. He wanted to show he can challenge these all too easily accepted rules. We can understand Cardano's enterprise in the Aliza as an exercise in subtlety. In his famous work, De Subtilitate (Cardano, 1550), he defines subtlety as "a certain mental process whereby sensible things are perceived by the senses and intelligible things are comprehended by the intellect, although with difficulty". Subtlety thus explores the borders of human comprehension and negative quantities are situated at such border. By challenging the rules of signs he reacted against what Stendhal called "hypocrisy in mathematics".

\section{Larger than infinity}

Several historians of mathematics have pointed out that some major mathematicians of the sixteenth and seventeenth century believed that negative numbers were larger than infinity. From our reading of the original sources we believe that such interpretations are unwarranted. Statements about numbers greater than infinity occur in early mathematical treatments of infinitesimals and summation of series. They do not refer to negative

${ }^{6}$ Cardano 1663, IV, 399: "Et ideo patet communis error dicentium, quod $\mathrm{m}$. in m. producit p. neque enim magis $\mathrm{m}$. in $\mathrm{m}$. producit $\mathrm{p}$. quam $\mathrm{p}$. in p. producat $\mathrm{m}$.", (this and subsequent translations are mine). Later Christian Wolff (1732, I, 240) uses the same diagram to prove the rules of sign for multiplication. 
numbers as such but expressions in involving division by negative quantities. We will here discuss the two most important ones.

\subsection{John Wallis (1616-1703)}

While he was Savilian professor of geometry at Oxford, John Wallis wrote two of his most important works, one on conic sections and the other on infinitesimal quantities. In the latter one, titled Arithmetica Infinitorum of 1656 he advanced the idea that, when dividing a positive number by a negative one, the result is larger than infinity. The reasoning leading to this conclusion is found in proposition 104 (see Figure 4). A series of reciprocals $1 / a$ grows to zero when $a$ becomes very large and to infinity when $a$ is becomes zero. Now, as you cross zero you get to negative denominators. Extending the reasoning, numbers divided by zero become infinite and if you go beyond that, you arrive at values larger than infinity. Although we have to understand this surprising conclusion within the context in which it appears - the quadrature of curves with equations having negative indices - the statement is nevertheless unambiguous: the ratio of a positive number to a negative one is a rationem plusquam infinitam, "a ratio greater than infinity".

\section{P R P. CIV. Thsorensa.}

I deniq; ejufmodi Figura AD? s fic continuo $\rightarrow$ decrefeat juxta feriem quz fit reciproca directa indicem habenri unitate majorem; habebit illa ad Parallelogrammum iaferiptum rationem plusquam infinitam: qualem nompe habere fupponatur numerus pofitivus ad numerum negativum, five minorem nihilo. Neinpe eam, quam habet 1 ad indicem uritate auctum.

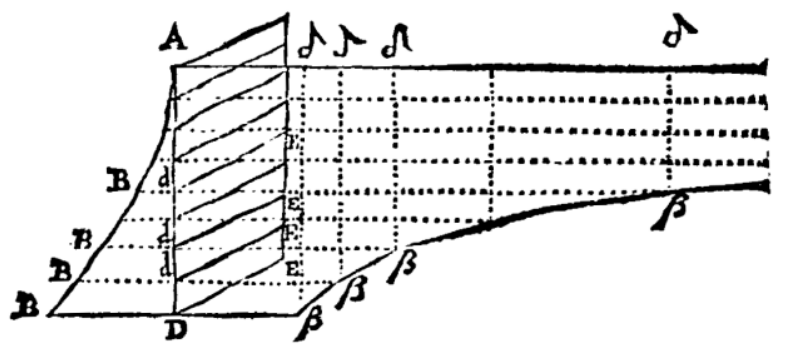

Puta cum indices feriei fecundanorum, Tertianorum Quartanorum, \&c. fint $2,3,4,8 \%$ (nnitate majores,) indices feriesum illis reciprocarum erunt $-2,-3,-4$, \&c. qui quamvis unitate au!geantur (juxta Prop. 64. )mancbunt tamen Hegativi,puta $-2+1=-1,-3+1=-2, \ldots+1=-3,8 c_{0}$ \& propterea ratio quan habet 1 ad indices illos lic auctos, pusec $r$ ad $-1,1$ a l -2 , i d -3 , \&c. major erit quara infinita, five 1 ad $o_{;}$quia nempe rationum confequentes fune minores quamo.

Figure 4: Wallis arguing that when a number is divided by a negative it becomes larger than infinity (from the Arithmetica infinitorum, p. 78) 
For some unknown reason several historians of mathematics misunderstood Wallis as if he claimed that negative numbers in themselves were greater than infinity. William Rouse Ball $(1912,293)$ writes "It is curious to note that Wallis rejected as absurd the now usual idea of a negative number as being less than nothing, but accepted the view that it something greater than infinity". We will see below that Wallis did not reject at all numbers less zero. In fact, Wallis can be considered as the inventor of the number line for negative quantities (see below). Morris Kline (1972; 1990, 253), possibly inspired by Ball, also completely misses the point: "Though Wallis was advanced for his times and accepted negative numbers, he thought they were larger than infinity but not less than zero". Some years later in his Loss of Certainty he writes $(1983,116)$ : “Though Wallis was advanced for his times and accepted negative numbers, he thought they were larger than $\infty$ as well as less than 0 ". Such incongruous misrepresentations caution us to always check the original sources.

\subsection{Leonhard Euler (1707-1783)}

About one century later Euler came to the same conclusion as Wallis through reasoning with divergent series. The Latin text De seriebus divergentibus [E247] was written in 1746, but not read to the Academy until 1754, and only published in 1760. Several English translations of the text have been published (Barbeau and Leah 1976; Kline 1983; Sandifer 2006).

6. 7. Defenfores igitur fummarum ferierum diuergen: tium ad hoc infigne paradoxon conciliandum, fubtile magis, quam verum, difcrimen inter quantitates negatiuas ftatuinit; dum alias nilhilo minores, alias vero infinito maiores, feir plusquam infinitas effe arguunt. Alium fcilicet valorem ipfinş-x agnofci debere, quando ex fubtractione numeri maioris $a+x$, a minori a oriri concipitur, alium vero, quando feriei illi $x+2+4+8+16+$ etc. aequalis reperitur, atque ex diuifione numeri $+\mathbf{I}$ per $-I$ nafcitur ; illo guippe cafu effe numerum nihilo minorem, hoc vero infinito maiorem. Maioris confirmationis gratia afferunt hoc: exemplum fractionum :

$$
\frac{1}{4}, \frac{x}{3}, \frac{x}{3}, \frac{x}{1}, \frac{x}{6}, \frac{1}{-1}, \frac{1}{-2}, \frac{x}{-3}, \text { etc. }
$$

quae cum prioribus terminis crefcens perfpiciatur, etiam continuo crefcere fit cenfenda; vnde concludunt fore $\frac{x^{\prime \prime}}{-1}>\frac{1}{0}$ et $\frac{x}{-1}>\frac{x}{-1}$, ficque porro : ideoque quatenus $\frac{x}{-x}$ per $-I$ et $\frac{x}{\sigma}$ per infinitum $\omega$ exprimitur, effe $-x S \sim$, multóque magis $=\frac{-1}{2}>\cdots:$ qúo pacto abfurditatem apparentem illari fatis ingeniofe a fe propellunt.

Figure 5: Fragment of Euler's text discussing division by a negative number

Euler's observations are based on the expansion posed by Leibniz in 1713 in which

$$
\frac{1}{(1-x)}=1+x+x^{2}+x^{3}+\cdots
$$

Euler begins the paragraph by stating that those who defend the idea of summing divergent series can resolve this paradox in a subtle way by discriminating between 1) quantities that become negative, 2) that stay less than zero, and 3) that become more than infinity. He then makes a distinction between two kinds of negatives: "Of the first sort is - 
1 , which is the difference between $a$ and its successor $a+1$. Of the second sort is the -1 that arises as $1+2+4+8+16+$ etc., which is equal to the number one gets by dividing +1 by -1 . In the first case, the number is less than zero, and in the second case it is greater than infinity". The first is a plain negative number as he later explains in his book on elementary algebra (Euler 1770). The second one is when you use $x=2$ in (0.3). You then arrive at

$$
\frac{1}{-1}=1+2+4+8+\cdots
$$

which according to Euler is greater than infinity. He then uses an argument analogous to Wallis:

This can be confirmed by the following example of a sequence of fractions:

$$
\frac{1}{4}, \frac{1}{3}, \frac{1}{2}, \frac{1}{1}, \frac{1}{0}, \frac{1}{-1}, \frac{1}{-2}, \frac{1}{-3}, \cdots
$$

where the first four terms are seen to grow, then grow to infinity, and beyond infinity they become negative. Thus the apparent absurdity is resolved in a most ingenious way.

Now again the idea, that dividing a number by a negative one leads to something larger than infinity, has been systematically been misunderstood. Kline writes "Euler, the greatest eighteenth-century mathematician believed that negative numbers are greater than infinity" (Kline 1981, 52) and later he later repeated "Euler concluded that -1 is larger than infinity" (Kline 1983, 144). Sandifer $(2006,179)$ "Euler is claiming that numbers greater than infinity are the same as numbers smaller than zero" and recently William Dunham $(2007,138)$ Euler "is willing to accept that "the same quantities which are less than zero can be considered to be greater than infinity". Despite the last quote, Wallis or Euler never claimed that negative numbers are greater than infinity. The misunderstanding becomes apparent from an article by Kline (1983) on Euler. Instead of expression (0.4) Kline writes that Euler obtained:

$$
-1=1+2+4+8+\cdots
$$

But that is taken already for granted that a positive divided by a negative is a negative, or $\frac{1}{-1}=-1$, which is precisely the identity questioned by Wallis and Euler. In fact, Euler had no problems at all with negative numbers. In his book on elementary algebra he writes that "we may say that negative numbers are less than nothing" (Euler 1822, 5) and he explains so by enumerating the negative numbers from zero "in the opposite direction, by perpetually subtracting unity", thus endorsing the idea behind the number line. Concerning the product of two negatives, Euler gives an argumentation for its positive result. Based on the proof that minus times plus is minus, therefore minus times minus should be different and therefore be plus. A second argument using the distributive law of multiplication (as Maestro Dardi), is added by the translator in the English edition. The rules for division by a negative are derived from the multiplication rules and thus pose no problem for Euler in his Algebra. 


\subsection{Jean le Rond d'Alembert (1717-1783)}

The discussion was not closed by Leibniz. Several eighteenth-century authors return to the question raised by Arnauld, such as Rolle (1690, 14-22). Maclaurin (1748, 6-7) does not refer to Arnauld but seems to be aware of the discussion. He considers $-a$ and $+a$ "equal as to quantity" but this does not mean that you can equate them in algebra as $+a=-a$. Their quality is the opposite of each other and "on account of this contrariety a negative quantity is said to be less than nothing".

Perhaps the most persistent in his struggle against the main presupposition of the number line - that negative numbers are smaller than zero - was d'Alembert. On several occasions both in the Encyclopédie as well as in his Opuscules he goes on about the idea of numbers smaller than nothing. D'Alembert was quite influential, not only through his work as a mathematician but also in his contacts with Royal circles. His contributions on mathematics in the Encyclopédie were printed and read long after his death. Under 'négatif' he writes: "negative quantities are those which are affected by the minus sign and which are considered by several mathematicians as smaller than zero. This last idea is false, as will see in one moment". ${ }^{7}$ His argumentation is based to some extent on the considerations of Wallis and Euler. One cannot just claim that negative numbers are smaller than zero because the passage from positive to negative does not always goes over zero. In the simple case of $y=x-a, y$ goes from positive to negative over zero. But in the case of $y=1 /(x-a)$ you will have $y=\infty$ when $x=a{ }^{8}$ So in contrast with Wallis and Euler, d'Alembert accepts that

$$
y=\frac{1}{-a}
$$

will be negative, but it becomes negative while passing $\infty$. He therefore concludes that it is wrong to say that negatives numbers are always smaller than zero. In his article on the 'negative', d'Alembert makes a distinction between addition and subtraction (for which the number line is perfectly adequate) and multiplication and division (for which it is not). Without naming Arnauld he also comments on the apparent anomaly where we started with: "Those who pretend that you cannot relate 1 to -1 and think that the ratio of 1 to -1 is different from -1 to 1 are making a double error. Firstly, we perform such algebraic operations every day and secondly the equality of the product of -1 with -1 , and of +1 by +1 , shows that 1 is to -1 as -1 is to 1 ".

${ }^{7}$ Diderot and d'Alembert, (1761-1790, 22, 289): “quantités négatives sont celles qui sont affectuées du signe - et qui sont regardées par plusieurs mathématiciens comme plus petit que zero. Cette dernière idée n'est pas juste, comme le verra dans un moment".

8 ibid. p. 300 : “Le passage du positif au négatif se fait toujours par zéro ou par l'infini. Soit, par exemple, $y$ $=x-a$ on aura $y$ positif tant que $x>a, y$ négatif lorsque $x<a$ et $y=0$ lorsque $x=0$; dans ce cas le passage se fait par zéro. Mais si $y=1 /(x-a)$ on aura $y$ positif tant que $x$ est $>a, y$ négatif lorsque $x$ est $<a$ et $y=\infty$ lorsque $x=a$; le passage se fait alors par infini"”.

9 ibid. p. 299 : “Ceux qui prétendent que $1 \mathrm{n}$ 'est pas comparable à -1 , et que le rapport entre 1 et -1 est différent du rapport entre -1 et 1 sont dans un double erreur, 1) parce qu'on divise tous les jours dans les opérations algébriques, 1 par $-1,2$ ) l'égalité du produit de -1 et -1 , et de +1 par +1 , fait voir que 1 est à -1 comme - 1 a 1 ". 


\section{The first use of the number line}

Before we get to our conclusion we may ask the question where the idea of a number line showing negative numbers originated. We find the answer in Wallis (1685) (see Figure 6). Remarkably Wallis introduces the number line for the purpose of illustrating addition and subtraction involving negative numbers in his work on algebra. When a man advances 5 yards from $\mathrm{A}$ and he returns 8 , how far is he then from his starting point? Wallis gives the answer -3 , as it is taught now in middle school. ${ }^{10}$

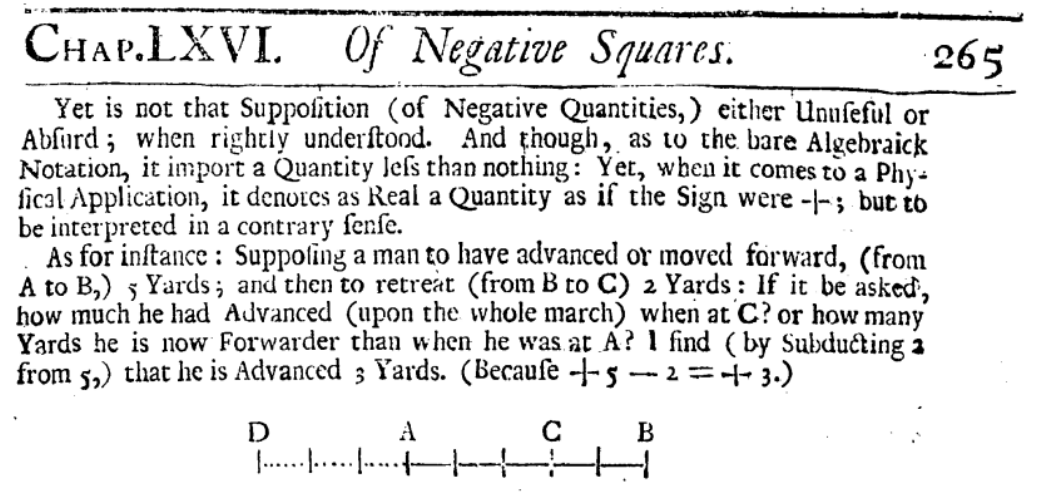

Figure 6: John Wallis introducing the number line in his Algebra

So the person responsible for the idea that a proportion between a positive quantity and a negative results in something larger than infinity, is also the first one to use the number line in a printed book. The idea was followed up by many others including Newton. Newton makes a distinction between "affirmative quantities" and "negative quantities". 11 A negative quantity arises when a large affirmative quantity is subtracted from a smaller one. And to illustrate the point Newton draws a line which amounts to a number line showing negative quantities.

\section{Conclusion}

We have shown that operations on negative quantities were a source of continuous controversy and discussion during the seventeenth and eighteenth centuries. John Wallis introduced the number line in his Treatise on Algebra while arguing that negative quantities are not absurd and that they can denote quantities in the physical world such as distances. He was the first to include a figure of the number line to illustrate addition and subtraction involving negative numbers. Arnauld raised the issue that our intuitions on proportions with smaller and larger quantities are contradicted by the division operation involving negative quantities. While he did not aim at the number line, his objections represent solid arguments against its use. The model of the number line breaks down once negative numbers are included in proportions. Leibniz considers Arnauld's objections as genuine ones and argued that negative quantities should be interpreted symbolically as we do with imaginary numbers. Leibniz was a master in mathematical symbolism who

${ }^{10}$ In Flanders, Belgium, this is taught in grade 7.

${ }^{11}$ Newton (1707, 3): "Quantitates vel affirmativae sunt seu majors nihilo, vel negativae seu nihilo minors", in the English translation of $(1720,3)$ : "Quantities are either affirmative, or greater than nothing; or negative, or less than nothing". 
understood the power of symbolic representation (Knobloch 2010). His reaction to the ongoing discussion allows us to draw important lessons from history: negative numbers are best understood in a symbolic context. Rules of arithmetic, including the rules of signs, can be blindly applied as operations on negative quantities because they are well founded and justified by the logistica speciosa or the symbolic algebra of the seventeenth century. This becomes especially clear when dividing by negative quantities. In their aim to give an arithmetical interpretation to division by negatives, both Wallis and Euler believed that such operations lead to numbers larger than infinity. Such interpretation not only confused their contemporaries but even $20^{\text {th }}$ century historians of mathematics who misunderstood Wallis and Euler in believing that negative quantities are larger than infinity.

When operations on negative quantities lead to heated debates between great mathematicians some centuries ago, it should come as no surprise that it also raises questions and difficulties in today's classrooms. We have argued that the development of symbolic mathematics represented one of the most important conceptual barriers in Early Modern mathematics. By the beginning of the nineteenth century - when symbolic algebra became universally accepted as a universal language of mathematics - discussions on the nature of negative numbers and their operations lose their relevance. The parallel between history and education concerning negative numbers becomes clear: once the conceptual barrier of symbolic reasoning is taken, difficulties get resolved. A consequence for mathematics education would be that operations on negative quantities are best taught as part of symbolic operations. The number line as a model for learning about negative quantities has a limited scope in pre-symbolic mathematics. Its use is limited to the operations of addition and subtraction. It breaks down when dealing with proportions and division involving negative numbers. History may also show that certain didactic approaches have their potential pit falls. The use of the number line in teaching negative numbers is in direct conflict with d'Alembert, who argues that most of the difficulties with Arnauld's identity arise from viewing negative numbers as smaller than zero.

Barry Mazur in his highly enjoyable and philosophical book Imagining numbers, spends a lot of attention to the question why we accept that minus times minus equals plus. He concludes (Mazur 2003, 102-3) that "there is, in fact, only one way to extend the definition of multiplication to all whole numbers, negative as well as positive, if we wish (we do!) 1 times any number $\mathrm{N}$ equal $\mathrm{N}$, and if we wish (we do!) the distributive law to hold". So this is an argument in favor of a proof as we know from the abbacists, which appeals to the properties of the distributive law. However, d'Alembert's definition of negative numbers: "those which are affected by the minus sign" is for us the most convincing. "Numbers affected with a sign" capture the way how negative numbers were introduced in history and how they fit within symbolic manipulations. We therefore believe that operations involving negative numbers, beyond addition and subtraction, should be taught within the context of early algebra.

\section{Acknowledgements}

The author is a fellow of the Research Foundation Flanders (FWO) Belgium and wishes to thank Jackie Stedall, Michael Matthews and several anonymous referees for their valuable comments on an earlier draft of this paper. The text was completed while the author was visiting fellow at the Sydney Centre for the Foundations of Science at Sydney University. All figures are cropped from digitized images of works in the public domain. Figures 1 
and 5 are from the Gallica project of the Bibliothèque nationale de France, Figure 2 from Girolamo Cardano. Strumenti per la storia del Rinascimento, http://www.cardano.unimi.it, Figure 3 from the Archimedes project of the Max-Planck-Institut für Wissenschaftgeschichte http://www.mpiwg-berlin.mpg.de, Figure 4 from Google books and Figure 6 from Early English Books Online.

\section{References}

Arnauld, A. \& Nicole, P. (1662) La logique, ou, L'art de penser contenant, outre les règles communes, plusieurs observations nouvelles propres à former le jugement. Paris: Charles Savreux. English translation, Vance Buroker J. (Ed., Tr) (1996) Logic, or the Art of Thinking. Cambridge: Cambridge University Press.

Arnauld, A. (1667) Nouveaux Éléments de géométrie. Paris: C. Savreux.

d'Alembert, J. le Rond, (1761-1780) Opuscules mathémathiques ou Mémoires sur différens sujets de géométrie, de méchanique, d'optique, d'astronomie. Paris: David : [then] Briasson : [then] C.-A. Jombert, 8 vols. in 7 books.

Ball, W. W. R. (1912) A Short Account of the History of Mathematics. London: Macmillan and co. (Dover reprint, 1960)

Barbeau, E. J. \& P. J. Leah (1976) Euler's 1760 paper on divergent series. Historia Mathematica, 3, 141-160.

Beberman, M. \& Meserve, Br. E. (1956) An exploratory approach to solving equations. The Mathematics Teacher, January 1956.

Brousseau, G. (1976) Les obstacles épistémologiques et les problemes en mathematiques. Recherches en didactique des mathématiques, 4/2, 165-198. Translated in N. Balacheff, M. Cooper, R. Sutherland and V.Warfield (Eds., Tr.) Theory of Didactical Situations in Mathematics. Didactique des mathématiques, 1970 - 1990, Kluwer, Dordrecht, 1983, 79-116.

Cardano, G. (1545) Ars Magna. Nürnberg: Johann Petreius, (English translation by Witmer, R. T., (Ed., Tr) (1968) Ars Magna or the Rules of Algebra. Cambridge, Mass.: M.I.T. Press, Reprinted by Dover Publications, New York, 1993).

Cardano, G. (1550) De Subititate, Libri XXI. Nuremberg: Ioannes Petreius.

Cardano, G. (1663) Opera omnia (10 vols.), Lyon: Jean Antoine Huguetan and Marc Antione Ravaud.

Carey, S. (2001) Cognitive foundations of arithmetic, evolution and ontogenesis. Mind and Language, 16, 37-55.

Dehaene, S. (1997) The Number Sense: How the Mind Creates Mathematics. Oxford, Oxford University Press.

Diderot, D. \& d'Alembert J. le Rond (Eds.) (1765) Encyclopédie ou Dictionnaire raisonné des sciences, des arts et des métiers (17 vols.), Paris: Briasson, (ed. 1779-82, 36 vols., Lausanne: Sociétés typographiques).

Dunham, W. (2007) The Genius of Euler: Reflections on His Life and Work. Washington: Mathematics Association of America.

Euler, L. (1754/55) De seriebus divergentibus. Novi Commentarii academiae scientiarum Petropolitanae 5, (1760, p. 205-237), reprinted in Euler, L. Opera Omnia I, vol. 14, p. 585-617.

Euler, L. (1770) Vollständige Anleitung zur Algebra, St.-Petersburg. 
Freudenthal, H. (1983) Didactical Phenomenology of Mathematical Structures. Dordrecht: Reidel.

Heeffer, A. (2007) Abduction as a strategy for concept formation in mathematics: Cardano postulating a negative. In Pombo O. \& Gerner A. (Eds.) Abduction and the Process of Scientific Discovery. Colecçáo Documenta, Lisboa: Centro de Filosofia das Ciências da Universidade de Lisboa, 179-194.

Heeffer, A. (2008) The emergence of symbolic algebra as a shift in predominant models. Foundations of Science 13 (2), 149-161.

Heeffer, A. (2010) The Symbolic Model for Algebra: Functions and Mechanisms, in L. Magnani,; W. Carnielli, Walter \& C. Pizzi (Eds.) (2010) Model-Based Reasoning in Science and Technology, Abduction, Logic, and Computational Discovery. Studies in Computational Intelligence, vol. 314, Heidelberg: Springer, 519-532.

Høyrup, J. (2007) Jacopo da Firenze's Tractatus Algorismi and Early Italian Abbaco Culture. Science Networks Historical Studies, 34, Basel: Birkhauser.

Høyrup, J. (2010) Hesitating progress: the slow development toward algebraic symbolization in abbacus-and related manuscripts, c. 1300 to c. 1550 . In A. Heeffer \& M. Van Dyck (Eds.) Philosophical Aspects of Symbolic Reasoning in Early Modern Mathematics, Studies in Logic, 26, (pp. 3-56). London: College Publications.

Franci, R. (Ed.), 2001, Maestro Dardi (sec. XIV) Aliabraa argibra. Dal manoscritto I.VII.17 della Biblioteca Comunale di Siena. Quaderni del Centro Studi della Matematica Medioevale, 26, Siena: Università di Siena.

Gericke, H. (1996), Zur Geschichte der negativen Zahlen. In J. Dauben, M. Folkerts, E. Knobloch \& H. Wußing (Eds.) (1996) History of Mathematics. States of the Ar., New York: Academic Press, 279-306.

Glaeser G. (1981) Epistémologie des nombres relatifs. Recherches en didactique des mathématiques, 2(3) 303-346.

Herscovics, N. (1989) Cognitive obstacles encountered in the learning of algebra. In S. Wagner \& C. Kieran (Eds.), Research issues in the learning and teaching of algebra (pp. 60-86). Reston, VA: National Council of Teachers of Mathematics; Hillsdale, NJ: Lawrence Erlbaum.

Kline, M. (1959) Mathematics and the Physical World. New York: Crowell (Dover reprint 1981).

Kline, M. (1972) Mathematical Thought from Ancient to Modern Times. Oxford: Oxford University Press, (reprinted in 3 vols. 1990).

Kline, M. (1980) Mathematics: The Loss of Certainty. Oxford: Oxford University Press.

Kline, M. (1983) Euler on Infinite Series. Mathematics Magazine, 56 (5), 307-314.

Howson, A. G., Harris T. \& R Sutherland, R. (1999) Primary school mathematics textbooks. London: Qualifications and Curriculum Authority.

Knobloch, E. (2010) Leibniz between ars characteristica and ars inveniendi: Unknown news about Cajori's 'master-builder' of mathematical notations. In Heeffer, A. \& van Dyck, M. (eds.), Philosophical Aspects of Symbolic Reasoning in Early Modern Mathematics. London: College Publications, 289-302.

Leibniz, G. W. (1712) Observatio, quod rationes sive proportiones non habeant locum circa quantitates nihilo minores, \& de vero sensu methodi infinitesimalis. Acta eruditorum, 167-9. 
Newton, I. (1707) Arithmetica universalis; sive de compositione et resolutione arithmetica liber. Cui accessit Hallieana Æquationum radices arithmetice inveniendi methodus. Cambridge: Typis Academicis.

MacLaurin, C. (1748) A treatise of algebra in three parts: containing, I. The fundamental rules and operations, II. The composition and resolution of equations of all degrees, and the different affections of their roots, III. The application of algebra and geometry to each other: to which is added an appendix concerning the general properties of geometrical lines. London: A. Millar and J. Nourse.

Mancosu, P. (1996) Philosophy of mathematics and mathematical practice in the seventeenth century. Oxford: Oxford University Press.

Margolis, H. (1993) Paradigms \& Barriers: How Habits of Mind Govern Scientific Beliefs. Chicago: University of Chicago Press.

Mazur, B. (2003) Imagining Numbers (particularly the square root of minus fifteen). London: Penguin.

Piaget, J. \& Garcia R. (1983) Psychogenèse et histoire des sciences. Paris: Flammarion. English translation by Feider, H. (Ed.) (1989) Psychogenesis and the History of Science. New York: Columbia University Press.

Prestet, J. (1675) Elemens des mathematiques, ou Principes generaux de toutes les sciences, qui ont les grandeurs pour objet. Contenant vne methode covrte et facile pour comparer ces grandeurs \& pour découvrir leurs rapports par le moyen des caracteres des nobres, \& des lettres de l'alphabeth. Paris: A. Pralard.

Rolle, M. (1690) Traité d'algebre; ou, Principes generaux pour resoudre les questions de mathematique. Paris: Chez Etienne Michallet.

Sandifer, E. C. (2006) How Euler Did It. Washington: Mathematics Association of America.

Sesiano, J. (1985) The appearance of negative solutions in Mediaeval mathematic., Archive for History of Exact Sciences, 32, 105-50.

Schrecker, P. (1935) Arnauld, Malebranche, Prestet, et la Theorie des Nombres Négatifs. Thalès, 2, 82-90.

Schubring, G. (2005) Conflicts between Generalization, Rigor, and Intuition, Number Concepts Underlying the Development of Analysis in 17-19th Century France and Germany. Heidelberg : Springer.

Smith, D. E. (1959) A Source Book in Mathematics. New York: Dover.

Stendhal (2002) Vie de Henry Brulard. Translated by John Sturrock, The Life of Henry Brulard. New York: The New York Review of Books, 2002.

Tanner, R.C.H. (1980) The Alien Realm of the Minus: Deviatory Mathematics in Cardano's Writings. Annals of Science, 37, 159-178.

Thomaidis, Y. \& C. Tzanakis (2007) The notion of historical ,parallelism“ revisited: historical evolution and students' conception of the order relation on the number line. Educational Studies in Mathematics, 66, 165-183.

Wallis, J. (1656) Johannis Wallisii, SS. Th. D. geometriae professoris Saviliani in celeberrimâ academia Oxoniensi, operum mathematicorum pars altera qua continentur de angulo contactus \& semicirculi, disquisitio geometrica. De sectionibus conicis tractatus. Arithmetica infinitorum: sive de curvilineorum quadraturâ, \&c. Ecclipseos Solaris observation. Oxonii: typis Leon: Lichfield academiae typographi, veneunt apud Octav. Pullein Lond. Bibl. 
Wallis, J. (1685) A treatise of algebra, both historical and practical shewing the original, progress, and advancement thereof, from time to time, and by what steps it hath attained to the heighth at which it now is: with some additional treatises ... Defense of the treatise of the angle of contact. Defense of the treatise of the angle of contact. Discourse of combinations, alternations, and aliquot parts. Discourse of combinations, alternations, and aliquot parts. London : Printed by John Playford, for Richard Davis.

Wolff. C. von (1732) Elementa matheseos universae Vol. 1: Qui Commentationem de Methodo Mathematica, Arithmeticam, Geometriam, Trigonometriam Planam, et Analysim, tam Finitorum quam Infinitorum complectitur. Genevæ: Apud MarcumMichaelem Bousquet \& Socios. 